\title{
The role of family structure and parenting in first year university adjustment
}

\author{
Verushka Zaskia Daniels', Eugene Lee Davids',2 \\ and Nicolette Vanessa Roman' (iD
}

\begin{abstract}
The first year of university creates new experiences and challenges for first years and lays the foundation for the subsequent years of study. This first year has implications for academic development, mental health, and well-being of students and subsequently student retention. The majority of South African university students stay within their familial home unlike their international counterparts. The family may therefore play a contributory role in adjustment to university but this role is somewhat unclear. The current study therefore aimed to establish the associations between university adjustments of first year students, family structure, and parenting. The study employed a cross-sectional design, with a sample of 556 first year undergraduate students at a South African university. The data were collected using an electronic selfadministered questionnaire on a secure online platform using the Perceived Parental Autonomy Support Scale and the College Adaptation Questionnaire. Data analysis included hierarchical regression analyses and one-way analyses of variance to determine and compare the relationships between the variables. The results suggest that students from two-parent families were more adjusted than those from one-parent families. Autonomy-supportive parenting predicted positive university adjustment for the total sample, but only maternal autonomy-supportive parenting predicted good adjustment for students in two-parent families. This study highlights the potential role parents and families may play in the adjustment of first year students to university. This is particularly relevant in South Africa where many students are first-generation students, are challenged in transitioning to university, and this may have subsequent mental health-related challenges.
\end{abstract}

\section{Keywords}

Adjustment, family structure, first year students, parenting, university

\footnotetext{
'Child and Family Studies Programme, Department of Social Work, University of the Western Cape, South Africa

${ }^{2}$ Adolescent Health Research Unit, Division of Child \& Adolescent Psychiatry, University of Cape Town, South Africa
}

\section{Corresponding author:}

Eugene Lee Davids, Adolescent Health Research Unit, Division of Child \& Adolescent Psychiatry, University of Cape Town, 46 Sawkins Road, Rondebosch, 7700, Cape Town, South Africa.

Email: davidse.psych@gmail.com 
Adjusting to university is a process in which students' psychological and behavioural aspects are shaped to establish an identity as a university student (Quan, Zhen, Yao, \& Zhou, 2014). Students entering university face many stressful experiences; these are often part of the transition from high school to university (Parker, Hogan, Eastabrook, Oke, \& Wood, 2006). Developmentally, university students are emerging adults transitioning between adolescence and adulthood (Arnett, 2000). Many emerging adults aren't completely autonomous and responsible beings and therefore their parents/caregivers are left to play an important part in their transition to university (Schwartz et al., 2009), and this makes adjusting to university somewhat challenging.

The difficulty in adjusting to university, according to Sharma (2012), is a result of the disjuncture between students' expectation versus the reality of what university is all about. The first year university experience often determines completion or termination of studies in subsequent years (Bojuwoye, 2002; Dyson \& Renk, 2006). This is among the first encounters in the adjustment to university, setting the tone for mental health and academic performance (Bojuwoye, 2002; Dyson $\&$ Renk, 2006). When students are able to adapt to the new university environment and successfully adjust to the transition, a more positive university experience is more evident (Sharma, 2012). For many South African students, the basic needs related to campus life are not fully addressed (these include financial resources, food, clothing, and accommodation) and hampers the adjustment to university and campus life (Bojuwoye, 2002). In addition, to these basic needs not been fully addressed are concerns that this lowers their self-confidence further. Many South African students find that poverty and the lack of resources add additional stress on their adjustment to university (Pillay \& Ngcobo, 2010). Many students, however, lack the necessary skills to assist in their adjustment to university, and their immediate support system (such as family and friends) is either non-existent or willing but unable to support them (Akoojee \& Nkomo, 2007). The many uncertainties and self-doubt faced by these students in this transition to university, the importance of having some sense of belonging within their family, may act as a protective factor to future psychopathologies related to this adjustment. The contributory role of the family, however, remains unclear within higher education (Dyson \& Renk, 2006) and more so in developing countries, like South Africa (Rodríguez, Tinajero, \& Paramo, 2017).

South African families are diverse due to their rich historical and societal background. Families where children are raised in households with only one parent are common (Gould \& Ward, 2015), and the number of extended family members who co-reside within a household is often large and unique (Amoateng, Heaton, \& Kalule-Sabiti, 2007). Research examining family structure has suggested that two-parent families have an advantage over one-parent families due to the increased availability of resources (Magnuson \& Berger, 2009). But, it is the quality of the parent-child relationship that remains more important than the number of parents involved (Sun \& Li, 2011). The father-child relationship is often silent in parenting research but this relationship offers a unique perspective and understanding (Cabrera, Volling, \& Barr, 2018). In addition, parental attitudes and behaviours among mothers and fathers are often different across gender and might have implications on the home environment which influences the parent-child relationship (Tavassolie, Dudding, Madigan, Thorvardarson, \& Winsler, 2016).

The parent-child relationship and interaction, from the perspective of Self-Determination Theory, are more important to the adjustment of a young person when characterised by autonomysupportive parenting (Joussemet, Landry, \& Koestner, 2008). Autonomy-supportive parenting is when parents create a climate which satisfies the need for making autonomous choices and reasoning (Soenens, Vansteenkiste, \& Sierens, 2009; Vansteenkiste \& Ryan, 2013). Autonomy-supportive parenting often sees parents displaying nurturance and care that is warm, supportive and encourages involvement within the parent-child relationship (Joussemet, Koestner, Lekes, \& Landry, 2005). In contrast, parenting that frustrates the need for autonomy usually displays high levels of 
psychologically controlling behaviours which negatively affects adjustment (Joussemet et al., 2008). Parents who are autonomy-supportive assist in developing a sense of self-awareness in the young person (Soenens \& Vansteenkiste, 2005) and when entering university, these students (or young people) are able to recognise their emotions and seek appropriate help (Sommer \& Dumont, 2011). Making decisions, as well as efforts and intentions to study, are established independently, promoting resilience to the challenges of university leading to better coping and adjustment (Sharma, 2012). Autonomy-supportive parenting is often associated with improved well-being and high sense of internal motivation, allowing students to function better and adjust well to the demands of transitioning to university (Grolnick, 2003; Marbell \& Grolnick, 2012). Psychologically controlling parents, on the contrary, impose their wishes upon their children, resulting in a lack of internal motivation which hinders the adjustment of students and yields poorer academic outcomes (Baker, 2004; Grolnick \& Pomerantz, 2009).

\section{The current study}

Adjusting to the challenges and demands of university during the first year of study is important. The adjustment during this period has implications on the completion or termination of subsequent years of study (Dyson \& Renk, 2006). In South Africa, first year university dropout rates are averaged at $50 \%$. This high dropout rate is comprised largely of students from lower socio-economic backgrounds (Akoojee \& Nkomo, 2007). The high cost of university has implications for the entire family of these students from lower socio-economic backgrounds. This places additional pressure on these students to adjust to university, to ensure they graduate and enter the job market to improve the familial life circumstances (Bojuwoye, 2002; Lourens \& Smit, 2003). For many this is challenging as the increased access to university has not been accompanied with sufficient support to equip students who require skills in their adjustment to university (Beckmann, 2008). In addition, the families of these students are often unable to assist in their transition to university (Akoojee \& Nkomo, 2007). The South African familial context is varied, with many children raised in oneparent households often headed by mothers (Roman, 2011). Literature, both South African and international, suggest differences in students who are raised in one- and two-parent families, largely due to the pressured and complex role of being a single parent (Deleire \& Kalil, 2002; Magnuson \& Berger, 2009). Dyson and Renk (2006) suggest the important role of parents in facilitating students' adjustment to university, but the family remains an overlooked factor highlighting the need to understand the familial role in facilitating adjustment to university. The current study, therefore, aimed to investigate the relationship between first year students' adjustment to university, family structure, and parenting. The study was guided by the following questions: (1) What is the family structure among first year university students? (2) What is the prevalence of perceived parental (for both mothers and fathers) autonomy support and university adjustment among first year students? (3) Is there a significant difference between perceived parental autonomy support and university adjustment of students from one- and two-parent families? and (4) Does family structure and perceived parental autonomy support predict university adjustment of first year students?

\section{Method}

A quantitative study with a cross-sectional design was employed. The study aimed to examine the associations between family structure and parenting in adjustment to university among first year students. Students at a university in the Western Cape, South Africa, were recruited using stratified random sampling. 
Table I. Demographic profile of participants.

\begin{tabular}{lcc}
\hline Variables & Frequency & Percentage \\
\hline Gender & & \\
Male & 224 & 40.3 \\
Female & 332 & 59.7 \\
Faculty & & \\
Arts & 141 & 25.4 \\
Natural Science & 111 & 20 \\
Economic Management Sciences & 110 & 19.8 \\
Other & 194 & 34.9 \\
Language & & \\
English & 235 & 42.3 \\
Afrikaans & 74 & 13.3 \\
isiXhosa & 179 & 32.2 \\
Other & 68 & 12.4 \\
Living arrangements & & \\
Campus residence & 208 & 37.4 \\
Off-campus / family home & 348 & 62.6 \\
Parents' education & & 8.5 \\
Primary & 47 & 46 \\
$\quad$ Secondary & 256 & 39 \\
Tertiary & 217 & 6.5 \\
Post-graduate & 36 & 57.4 \\
Family structure & & 42.6 \\
Two parents & 319 & \\
One parent & 237 & \\
\hline
\end{tabular}

\section{Participants}

The participants were 556 first year university students, with a mean age of 18.9 years $(S D=1.13)$, of whom the majority were female ( $n=332,59.7 \%$; see Table 1$)$. The most prevalent responses per faculty were from the Arts Faculty $(n=141,25.4 \%)$, followed by Natural Science $(n=111,20 \%)$ and Economic and Management Sciences $(n=110,19.8 \%)$. English was the most prevalent language spoken by respondents $(n=235,42.3 \%)$. The majority of respondents were from areas in close proximity to the University and lived at home with their families $(n=348,62.6 \%)$, while 208 $(37.4 \%)$ respondents lived without family in either a campus or private residence. Most parents had a secondary school qualification $(n=256,46 \%)$. The majority of respondents were from twoparent families $(n=319,57.4 \%)$.

\section{Instrument}

The data were collected by means of a computerised self-administered questionnaire (Rubin \& Babbie, 2001) which allowed the respondents to receive the questionnaire in a link format via email and submit the completed questionnaire electronically. The questionnaire was available in English and consisted of three sections, namely, (1) Demographics, (2) Perceived Parental Autonomy Support Scale (P-PASS) (Mageau et al., 2011), and (3) College Adaptation Questionnaire (CAQ) (Crombag, 1968). Both the P-PASS and CAQ were developed in largely Western contexts 
and have not been adapted for use within a South African setting. The P-PASS is a 24-item scale used to assess perceived parenting behaviours which can be categorised into autonomy-supportive and psychologically controlling parenting domains. Participants rated both maternal and paternal perceived behaviours on a 5-point Likert-type scale $(1=$ strongly disagree and $5=$ strongly agree $)$. An example of the type of questions in the P-PASS would be: 'My parents used guilt to control me' or 'My parents encouraged me to be myself'. A total of 12 items make up each of the autonomy support and psychological control domains. The CAQ is an 18-item scale used to assess students overall adjustment to university on two domains, namely, good adjustment determined by 8 items and poor adjustment using 10 items rated on a 5-point Likert-type scale $(1=$ strongly disagree and $5=$ strongly agree). Examples of the questions in the CAQ include the following: 'I find it difficult to adjust to student life' and 'I am very satisfied with the course of my studies'. Cronbach's alpha scores in the study were considered acceptable as suggested by Tavakol and Dennick (2011) that many studies have reported acceptable alpha scores to range between .70 and .95: Mother Autonomy Support $=.87$, Father Autonomy Support $=.98$, Mother Psychological Control=.84, Father Psychological Control=.95, Good Adjustment $=.76$, and Poor Adjustment $=.62$.

\section{Procedure}

Once ethical clearance was obtained from the University of the Western Cape, access was granted to email addresses of participants by the University's Information Technology Department. Electronic invitations and information sheets were sent to the participants' using an email invitation which contained an embedded link to the online platform containing the consent form. In addition, teaching staff informed participants about the study. When agreeing to voluntarily partake in the study and completing the written informed consent form, the participants were directed to a secure online platform where the data were collected. The duration of completing the electronic self-administered questionnaire was approximately $15 \mathrm{~min}$.

\section{Ethical considerations}

Ethical approval for the research was obtained from the Faculty of Community and Health Sciences Research Ethics Committee at the University of the Western Cape. The ethical principles which guided the research study were (1) written informed consent, (2) anonymity, (3) privacy and confidentiality, as well as (4) voluntary participation as outlined in the ethical clearance application to the institution. In addition, to uphold anonymity in the study, the secure online platform, was hosted via a restricted link and confidentiality was maintained by disabling the 'cookies' settings on the survey, while IP addresses were not collected.

\section{Data analysis}

The collected data were analysed using the Statistical Package for the Social Sciences (SPSS), Version 23. Both descriptive and inferential statistics were used in addressing the overall aim of the study. Pearson's correlation analysed the association between variables, while multiple one-way analyses of variance (ANOVAs) established differences between one- and two-parent families. The analyses also included separate hierarchical regression analyses for predicting the effects of family structure and parenting on university adjustment (Terreblanche \& Durrheim, 2004). Pearson's correlation was performed to establish initial associations between variables before performing the hierarchical regression analyses to answer the research question: Does family structure and perceived parental autonomy support predict university adjustment of first year students? The 
assumptions associated with each of the statistical tests used in the study were examined and met the associated criteria. The effect sizes to determine the practical significance of the associations were guided by the following as outlined by Cohen (1988) and Kanengoni, Ngarambe, and Buitendach (2017): . $3<a<.5=$ medium effect and $.5<a<1=$ larger effect.

\section{Results}

\section{Descriptive statistics}

What is the prevalence of perceived parental autonomy support and university adjustment? In examining types of parenting across the entire sample, maternal autonomy-supportive parenting obtained the highest rating $(M=3.56 ; S D=1.05)$ and paternal psychological control obtained the lowest $(M=1.61$; $S D=1.53$; see Table 2). In examining types of parenting in one- and two-parent families, as outlined in Table 2, similar results were found. In examining adjustment across the entire sample, good adjustment obtained the highest rating $(M=3.45 ; S D=0.69)$ and poor adjustment the lowest $(M=2.73 ; S D=0.78)$. An examination of adjustment in one- and two-parent families found similar results (see Table 2).

An examination of the minimum and maximum scores as well as the standard deviations was performed. These were performed to determine that scores weren't three standard deviations above or below the mean score. Skewness and kurtosis were also performed to confirm that the distribution of scores were in the normal range (see Table 2). Table 2 presents the means and standard deviations for the variables examined in the study by family structure.

\section{Inferential statistics}

Is there a significant difference between perceived parental autonomy support and university adjustment of students from one- and two-parent families? When examining the descriptive statistics as obtained by the measures in the study, differences between parenting and adjustment were tested using the one-way ANOVA for the various domains of parenting and adjustment. The results from the one-way ANOVAs as presented by the $F$-statistic in Table 2 suggest that significant differences were established between one- and two-parent families for maternal $\left(F(1,554)=18.25, p=.001 ; \eta^{2}=.031\right.$; small effect) and paternal autonomy-supportive parenting $\left(F(1,554)=289.46, p=.001 ; \eta^{2}=.343\right.$; medium effect) as well as in paternal psychological control $\left(F(1,554)=227.29, p=.001 ; \eta^{2}=.291\right.$; small effect) between the two groups. Those from two-parent families obtain higher ratings for maternal and paternal autonomy-supportive parenting and paternal psychological control than oneparent families. In addition, a significant difference was found between one- and two-parent families for good adjustment $\left(F(1,553)=5.19, p=.02 ; \eta^{2}=.009\right.$; small effect; see Table 2) where participants from two-parent families obtained slightly higher ratings for good adjustment.

Does family structure and perceived parental autonomy support predict university adjustment of first year students? When observing the total sample, the results in Table 3 suggest that good adjustment was positively correlated with both mother $(r=.15 ; p<.05)$ and father autonomy-supportive parenting $(r=.14$; $p<.05)$, and this was similar for two-parent families for both mother and father autonomy-supportive parenting $(r=.24, p<.05 ; r=.18, p<.05)$. Small effects are observed in these associations. A significant negative relationship exists between good adjustment and mother psychological control $(r=-.12 ; p<.05)$ in the total sample, which was similar for two-parent families $(r=-.18$; $p<.05)$ only, with small effects observed. 


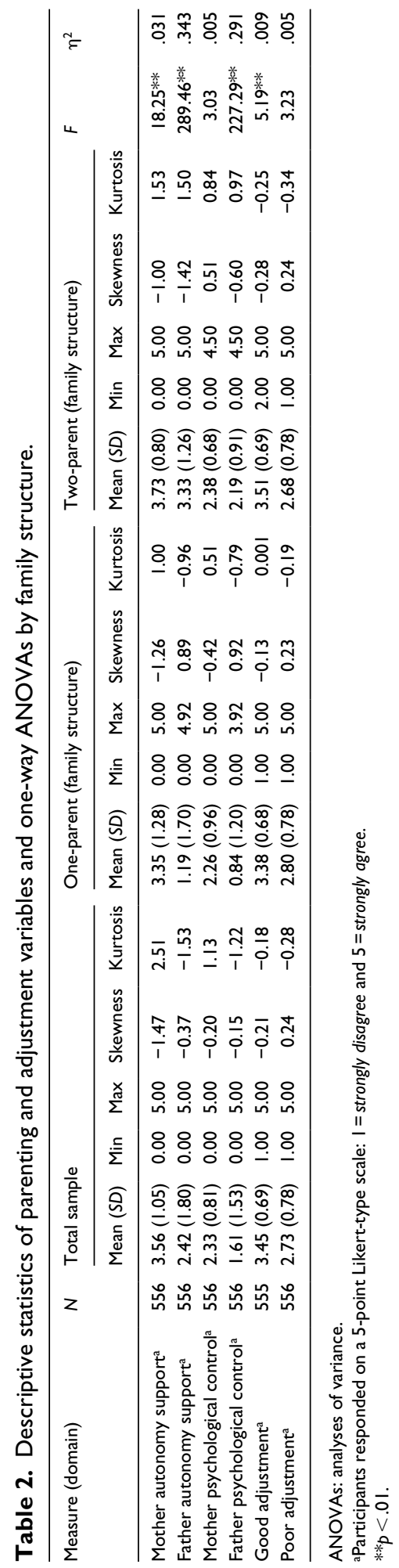


Table 3. Variable correlations.

\begin{tabular}{|c|c|c|c|c|c|c|}
\hline \multirow[t]{2}{*}{ Variables } & \multicolumn{2}{|l|}{ Total sample } & \multicolumn{2}{|c|}{ Two-parent families } & \multicolumn{2}{|c|}{ One-parent families } \\
\hline & $\begin{array}{l}\text { Good } \\
\text { adjustment }\end{array}$ & $\begin{array}{l}\text { Poor } \\
\text { adjustment }\end{array}$ & $\begin{array}{l}\text { Good } \\
\text { adjustment }\end{array}$ & $\begin{array}{l}\text { Poor } \\
\text { adjustment }\end{array}$ & $\begin{array}{l}\text { Good } \\
\text { adjustment }\end{array}$ & $\begin{array}{l}\text { Poor } \\
\text { adjustment }\end{array}$ \\
\hline Mother autonomy support & $.15^{* *}$ & $-.20 * *$ & $.24 * *$ & $-.27^{* *}$ & .07 & $-.13^{*}$ \\
\hline Father autonomy support & $.14^{* *}$ & $-.14 * *$ & $.18 * *$ & $-.19 * *$ & .03 & -.06 \\
\hline Mother psychological control & $-.12 * *$ & $.97 *$ & $-.18 * *$ & $.22 * *$ & -.09 & -.01 \\
\hline Father psychological control & .01 & .01 & -.07 & $.16 * *$ & -.02 & -.02 \\
\hline
\end{tabular}

$* * p<.01 ; * p<.05$.

A significant negative correlation for poor adjustment and mother autonomy support $(r=-.20$; $p<.05)$ and father autonomy support $(r=-.14 ; p<.05)$ was found for the total sample as well as in two-parent families, for mother and father autonomy support, respectively $(r=-.27, p<.05$; $r=-.19, p<.05)$. While in one-parent families, poor adjustment was significantly negatively correlated with mother autonomy support only $(r=-.13 ; p<.05)$. These associations suggest a small effect size in the associations. Poor adjustment, however, and mother psychological controlling parenting were significantly positively correlated in both the total sample $(r=.97 ; p<.05)$ and two-parent families $(r=.22 ; p<.05)$, with a larger effect in the association for the total sample and a small effect seen in two-parent families. Poor adjustment and father psychological controlling parenting were also significantly positively correlated $(r=.16 ; p<.05)$ in two-parent families only, with a small effect observed.

As can be seen in Table 3, the significant Pearson's correlations ranged from .12 to .97, indicating that the coefficients of determination of the significant results ranged from $1.44 \%$ to $94.09 \%$. This suggests that the practical significance of the results ranged from small to large (Field, 2013).

Using hierarchical regression analysis, in Step 1 for the total sample, mother $(\beta=.14 ; p=.001$; small effect) and father autonomy-supportive parenting $(\beta=.12 ; p=.01$; small effect) significantly positively predicted good adjustment (see Table 4 ). Autonomy-supportive parenting was added in the first step of the analysis as dependent variables as it is suggested by theory to be associated with prosocial developmental outcomes as a known predictor (Field, 2013; Grolnick, 2003). In Step 2, when adding mother and father psychological controlling parenting, mother $(\beta=.13 ; p=.01$; small effect) and father autonomy-supportive parenting $(\beta=.20 ; p=.02$; small effect $)$ significantly positively predicted good adjustment, while mother psychological controlling parenting $(\beta=-.10$; $p=.05$; small effect) significantly negatively predicted good adjustment. A small practical effect is seen as a result of the incremental variance explained by the model. The final model explained $5 \%$ of the variance $\left(R^{2}=.06 ; F(2,550)=5.83, p=.003\right)$.

Furthermore, in Step 1 for two-parent families, only mother autonomy-supportive parenting $(\beta=.20 ; p=.001$; small effect) significantly positively predicted good adjustment. In Step 2, when adding mother and father psychological controlling parenting, mother autonomy-supportive parenting $(\beta=.17 ; p=.02$; small effect) still remained a significant and positive predictor for good adjustment. A small practical effect is seen as a result of the incremental variance explained by the model. The final model explained $7 \%$ of the variance presented for good adjustment in two-parent families $\left(R^{2}=.08 ; F(2,313)=2.72, p=.067\right)$. There were no significant predictors for good adjustment in one-parent families $\left(R^{2}=.02 ; F(2,232)=1.89, p=.15\right)$.

When using hierarchical regression analysis, in Step 1 for the total sample, both mother $(\beta=-.18 ; p=.001 ;$ small effect) and father autonomy-supportive parenting $(\beta=-.12 ; p=.01 ;$ small effect) significantly negatively predicted poor adjustment (see Table 5). In Step 2, when adding 
Table 4. Hierarchical regression analyses for good adjustment.

\begin{tabular}{|c|c|c|c|c|c|c|c|c|c|c|c|c|c|c|c|}
\hline & \multicolumn{5}{|c|}{ Total sample } & \multicolumn{5}{|c|}{ Two-parent families } & \multicolumn{5}{|c|}{ One-parent families } \\
\hline & $b$ & $S E b$ & $\beta$ & $t$ & $p$ & $b$ & $S E b$ & $\beta$ & $t$ & $p$ & $b$ & $S E b$ & $\beta$ & $t$ & $p$ \\
\hline \multicolumn{16}{|l|}{ Good adjustment } \\
\hline \multicolumn{16}{|l|}{ Step I } \\
\hline Constant & 3.02 & & & & & 2.71 & & & & & 3.21 & & & & \\
\hline MAS & 0.10 & 0.03 & .14 & 3.33 & $.00 *$ & 0.17 & 0.05 & .20 & 3.24 & $.00 *$ & 0.04 & 0.04 & .08 & 1.21 & .23 \\
\hline FAS & 0.05 & 0.02 & .12 & 2.84 & $.01 *$ & 0.05 & 0.03 & .09 & 1.55 & .12 & 0.02 & 0.03 & .04 & 0.67 & .51 \\
\hline \multicolumn{16}{|l|}{ Step 2} \\
\hline Constant & 3.26 & & & & & 3.11 & & & & & 3.37 & & & & \\
\hline MAS & 0.09 & 0.03 & .13 & 2.79 & $.0 I^{*}$ & 0.14 & 0.06 & .17 & 2.42 & $.02 *$ & 0.05 & 0.04 & .10 & 1.36 & .18 \\
\hline FAS & 0.07 & 0.03 & .20 & 2.33 & $.02 *$ & 0.10 & 0.05 & .10 & 1.19 & .24 & 0.05 & 0.06 & .13 & 0.86 & .39 \\
\hline MPC & -0.08 & 0.04 & -.10 & -2.0 & $.05 *$ & -0.12 & 0.08 & -.12 & -1.56 & .12 & -0.08 & 0.05 & -.11 & -1.44 & +.15 \\
\hline FPC & -0.06 & 0.05 & -.11 & -1.40 & .17 & -0.01 & 0.07 & -.02 & -0.27 & .79 & -0.07 & 0.09 & -.13 & -0.86 & 39 \\
\hline
\end{tabular}

MAS: mother autonomy support; FAS: father autonomy support; MPC: mother psychological control; FPC: father psychological control.

Step I: Good adjustment: Total sample $\Delta R^{2}=.04$, two parents $\Delta R^{2}=.06$, one parent $\Delta R^{2}=-.00$.

Step 2: Good adjustment: Total sample $\Delta R^{2}=.05$, two parents $\Delta R^{2}=.07$, one parent $\Delta R^{2}=-.0 \mathrm{I}$.

$*_{p}<.05$. Bold indicates significant values.

Table 5. Hierarchical regression analyses for poor adjustment.

\begin{tabular}{|c|c|c|c|c|c|c|c|c|c|c|c|c|c|c|c|}
\hline & \multicolumn{5}{|c|}{ Total sample } & \multicolumn{5}{|c|}{ Two-parent families } & \multicolumn{5}{|c|}{ One-parent families } \\
\hline & $b$ & $S E b$ & $\beta$ & $t$ & $p$ & $b$ & $S E b$ & $\beta$ & $t$ & $p$ & $b$ & $S E b$ & $\beta$ & $t$ & $p$ \\
\hline \multicolumn{16}{|l|}{ Poor adjustment } \\
\hline \multicolumn{16}{|l|}{ Step I } \\
\hline Constant & 3.3 & & & & & 3.72 & & & & & 3.16 & & & & \\
\hline MAS & -0.1 & 40.03 & -.18 & -4.39 & $.00 *$ & -0.23 & 0.06 & -.23 & -3.86 & $.00 *$ & -0.09 & 0.04 & -.15 & -2.28 & 3.02* \\
\hline FAS & -0.0 & 50.02 & -.12 & -2.81 & $.0 I^{*}$ & -0.06 & 0.04 & & & .14 & -0.04 & 0.03 & -.09 & -1.33 & 3.18 \\
\hline \multicolumn{16}{|l|}{ Step 2} \\
\hline Constant & 3.0 & & & & & 3.09 & & & & & 3.11 & & & & \\
\hline MAS & -0.1 & 0.04 & -.14 & -2.96 & $.00 *$ & -0.14 & 0.07 & -.14 & -2.06 & $.04 *$ & -0.09 & 0.05 & -.15 & -2.04 & $4.04^{*}$ \\
\hline FAS & -0.1 & 30.04 & -.30 & -3.64 & $.00 *$ & -0.13 & 0.05 & -.20 & -2.43 & $.02 *$ & -0.06 & 0.07 & -.14 & -0.90 & .37 \\
\hline MPC & 0.0 & 40.05 & .04 & 0.85 & .39 & 0.07 & 0.08 & .06 & 0.82 & .42 & 0.02 & 0.06 & .02 & 0.26 & .80 \\
\hline FPC & 0.1 & 50.05 & .23 & 2.85 & $.01 *$ & 0.16 & 0.07 & .19 & 2.17 & $.03 *$ & 0.04 & 0.10 & .06 & 0.40 & .69 \\
\hline
\end{tabular}

MAS: mother autonomy support; FAS: father autonomy support; MPC: mother psychological control; FPC: father psychological control.

Step I: Poor adjustment: Total sample $\Delta R^{2}=.05$, two parents $\Delta R^{2}=.07$, one parent $\Delta R^{2}=.02$.

Step 2: Poor adjustment: Total sample $\Delta R^{2}=.07$, two parents $\Delta R^{2}=. \mathrm{I}$ I, one parent $\Delta R^{2}=.0 \mathrm{I}$.

$*_{p}<.05$. Bold indicates significant values.

mother and father psychological controlling parenting, mother $(\beta=-.14 ; p=.001 ;$ small effect $)$ and father autonomy-supportive parenting $(\beta=-.30 ; p=.001$; medium effect) significantly and negatively predicted poor adjustment, while father psychological controlling parenting $(\beta=.23 ; p=.01$; small effect) significantly and positively predicted poor adjustment. A small practical effect is seen as a result of the incremental variance explained by the model. A variance of $7 \%$ explained the final $\operatorname{model}\left(R^{2}=.08 ; F(2,551)=7.68, p=.001\right)$. 
In Step 1 for two-parent families, only mother autonomy-supportive parenting $(\beta=-.23$; $p=.001$; small effect) significantly and negatively predicted poor adjustment. In Step 2, when adding mother and father psychological controlling parenting, both mother $(\beta=-.14 ; p=.04$; small effect) and father autonomy-supportive parenting $(\beta=-.20 ; p=.02$; small effect) significantly and negatively predicted poor adjustment, while father psychological controlling parenting $(\beta=.19 ; p=.03$; small effect) significantly and positively predicted poor adjustment. A small practical effect is seen as a result of the incremental variance explained by the model. The final model explained $11 \%$ of the variance for poor adjustment in two-parent families $\left(R^{2}=.12\right.$; $F(2,314)=6.83, p=.001)$.

In Step 1 for one-parent families, mother autonomy-supportive parenting $(\beta=-.15 ; p=.02$; small effect) significantly and negatively predicted poor adjustment. In Step 2, when adding mother and father psychological controlling parenting, mother autonomy-supportive parenting still remained ( $\beta=-.15 ; p=.04$; small effect) a significant and negative predictor for poor adjustment in one-parent families. A small practical effect is seen as a result of the variance explained by the model. The final model explained $1 \%$ of the variance for poor adjustment in one-parent families $\left(R^{2}=.03 ; F(2,232)=.15, p=.86\right)$.

\section{Discussion}

The aim of this study was to determine the role of family structure and parenting in first year university adjustment, which was guided by the four research questions outlined in the introduction and results section. Overall, the results suggest that the current sample of university students was well adjusted, most students were from two-parent families and their parents often used autonomy-supportive parenting practices. The findings regarding the family structure can be explained by what previous studies suggest as a result of increased resources in two-parent families allowing more access to tertiary education than in one-parent families (Magnuson \& Berger, 2009).

The current study results also indicate that family structure plays a role in the adjustment to university, and that it seemed that students from two-parent families were better adjusted than those from one-parent families. This is similar to the findings of Lamb (2012) which state that based on the assumption of both parents being loving and warm towards the child, family structure becomes important because of the secure physical and emotional environment provided by such parents. When the social environment enhances their basic psychological needs of competence, relatedness, and autonomy, students are more internally motivated and the family life is one such environment (Joussemet et al., 2008). This is not to say that one-parent households fair poorer than two-parent families, as issues such as inter-parental conflict might add additional stress to the adjustment within the familial home environment (Sun \& Li, 2011). Parents who have healthy relationships with their partners and support each other by sharing the parenting responsibility have lower stress levels which allow them to create a warm and supportive environment for their children (Lamb, 2012; Musick \& Meier, 2010). In contrast, parents who raise their children on their own have to fulfil double roles and this is exhaustive on the parent which may result in parents being less involved (Deleire \& Kalil, 2002; Grolnick, Price, Beiswinger, \& Sauck, 2007; Magnuson \& Berger, 2009). However, Sun and Li (2011) suggest that one-parent families may have little or no disruptions or inter-parental conflict in the family functioning which would provide similar outcomes for students in one-parent families as in two-parent families, where good parent-child interaction and a supportive environment are assumed. This is, however, not easily maintained in the South African context of one-parent families due to the socio-economic pressures which disrupt warm and supportive parenting environments (Bray \& Brandt, 2007). 
In this study, autonomy-supportive parenting was positively associated with good adjustment. This result could be a reflection of the link between positive parenting, positive behaviour, and well-being of children, which was found in previous research (Grolnick, Kurowski, Dunlap, \& Hevey, 2000; Guay, Ratelle, \& Chanal, 2008; Joussemet et al., 2008; Soenens et al., 2009; Vansteenkiste \& Ryan, 2013). It is suggested that the warmth and understanding which autonomysupportive parents display towards their child develop self-confidence and this places the emerging adult at ease when facing challenging tasks such as university adjustment (Katz \& Somers, 2015; Soenens, Vansteenkiste, \& Van Petegem, 2014). When parents are confident in their child's ability to manage developmental tasks on their own, they are autonomy supportive and allow children the personal space to initiate their own solutions (Grolnick \& Pomerantz, 2009; Soenens \& Vansteenkiste, 2005). Even when such young people fail at something, they are not judged by their parents, since autonomy-supportive parents acknowledge their child's abilities (Grolnick \& Pomerantz, 2009; Inguglia et al., 2016). Furthermore, the positive outcomes of autonomysupportive parenting become more essential as it results in better psychological well-being and increase students' internal motivation. Also, children have better educational outcomes when they are raised in warm and supportive environments compared to those raised in controlling environments (Amato \& Fowler, 2002; Baker, 2004; Inguglia et al., 2016; Marbell \& Grolnick, 2012; Soenens \& Vansteenkiste, 2005) and their psycho-social development is enhanced when parents are loving towards them (Lamb, 2012).

In terms of psychologically controlling parenting, results from the current study indicate that psychologically controlling parenting resulted in maladjustment. Parents become psychologically controlling when they are insecure of their child's natural developmental ability, and this suppresses the child's need for competence (Joussemet et al., 2008). University students should display an increased self-reliance and make decisions without much parental influence (Alt, 2014). Previous studies have found that behaviours such as psychological controlling parenting result in suicidal and anti-social behaviour (Madu \& Matla, 2003) and this may add to the existing pressures of university life. Since university students are faced with the new university environment in which they establish a different identity, their parenting perception may precipitate negative outcomes such as skipping class or not completing assignments during their adjustment to university (McClelland \& McKinney, 2016). In addition, the significance of these findings has highlighted the dire need for adequate support measures to students from oneparent families to ensure their successful adjustment into university, as the emotional environment for autonomy-supportive parenting in one-parent households is sometimes more challenging to maintain, in the presence of multiple roles and responsibilities held by the parent (Nixon, Greene, \& Hogan, 2015).

University support services may incorporate the findings of this study to enhance their existing interventions for first year students, such as mentoring and coaching programmes. The results could be used to support positive parenting interventions such as sending group emails to parents on how to be more supportive to students as well as including parents in university orientation programmes to provide insight into the many difficulties related to mental health and adjustment that their children might face. In addition, secondary schools may implement an initiative between parents, learners, and teachers to prepare the prospective students for the university adjustment transition, in which aspects of career guidance are combined with parenting behaviours and in such a manner raise students' self-awareness. The study has also contributed to the existing literature on university adjustment, by increasing knowledge about how family structure and parenting behaviour affect students' well-being and adjustment. This is particularly relevant in South Africa where many students are first-generation students and in addition to adjustment issues this often poses many mental health-related challenges. 
A limitation in the current study was the online method of data collection, which resulted in lower response rates since students often delete emails from unknown senders due to the high frequency of spam. The timing of the data collection during the seventh week of academic activity was another limitation, as this was peak time for students since they had a late start to the academic year due to national protests in the South African higher education sector. It would therefore be recommended to administer the survey via hard copy questionnaires to increase the response rates and to schedule data collection during the latter part of the first semester when the academic peak has decreased. The cross-sectional design was another limitation as it measures at one point in time, providing only a snapshot of the variables examined in the study. In addition, using selfreport measures also pose a potential risk to participants' responses as participants may answer in ways to present themselves more favourably. An added limitation when considering instrumentation would be the use of both the P-PASS and CAQ, which were developed in a Western context and not specifically adapted for a diverse context like South Africa.

\section{Conclusion}

Several studies have indicated the role of autonomy-supportive and psychologically controlling parenting on the well-being of children, and the family environment in which children are raised is emphasised as an important factor for the outcomes of children. The findings of this study not only support the existing research on parenting and family structure but also provide a snapshot of the landscape of the potential role parents and families play in the adjustment to university in a South African context.

\section{Funding}

The author(s) disclosed receipt of the following financial support for the research, authorship, and/or publication of this article: The financial assistance of the National Research Foundation (NRF) towards this research is hereby acknowledged. Opinions expressed and conclusions arrived at are those of the authors and not necessarily to be attributed to the NRF.

\section{ORCID iDs}

Eugene Lee Davids (iD https://orcid.org/0000-0002-3805-3904

Nicolette Vanessa Roman (iD https://orcid.org/0000-0002-4506-437X

\section{References}

Akoojee, S., \& Nkomo, M. (2007). Access and quality in South African higher education: The twin challenges of transformation. South African Journal of Higher Education, 21, 385-399.

Alt, D. (2015). First-year female college students' academic motivation as a function of perceived parenting styles: A contextual perspective. Journal of Adult Development, 22(2), 63-75. doi:10.1007/s10804-0149201-2

Amato, P. R., \& Fowler, F. (2002). Parenting practices, child adjustment, and family diversity. Journal of Marriage and Family, 64, 703-716.

Amoateng, A. Y., Heaton, T. B., \& Kalule-Sabiti, I. (2007). Living arrangements in South Africa. In Families and households in post-apartheid South Africa: Socio-demographic perspectives (pp. 43-59). Cape Town, South Africa: HSRC Press.

Arnett, J. J. (2000). Emerging adulthood: A theory of development from the late teens through the twenties. American Psychologist, 55, 469-480.

Baker, S. R. (2004). Intrinsic, extrinsic, and amotivational orientations: Their role in university adjustment, stress, well-being, and subsequent academic performance. Current Psychology, 23, 189-202. 
Beckmann, J. (2008). Aspects of student equity and higher education in South Africa. South African Journal of Higher Education, 22, 773-788.

Bojuwoye, O. (2002). Stressful experiences of first year students of selected universities in South Africa. Counselling Psychology Quarterly, 15, 277-290. doi:10.1080/09515070210143480

Bray, R., \& Brandt, R. (2007). Child care and poverty in South Africa. Journal of Children \& Poverty, 13, 1-19. doi:10.1080/10796120601171187

Cabrera, N. J., Volling, B. L., \& Barr, R. (2018). Fathers are parents, too! Widening the lens on parenting for children's development. Child Development Perspectives, 12, 152-157. doi:10.1111/cdep.12275

Cohen, A. (1988). Statistical power analysis for the behavioural sciences (2nd ed.). Mahwah, NJ: Lawrence Erlbaum.

Crombag, H. F. M. (1968). Studiemotivatie en studie attitude. Groningen, The Netherlands: Wolters.

Deleire, T., \& Kalil, A. (2002). Good things come in threes: Single-parent multigenerational family structure and adolescent adjustment. Demography, 39, 393-413.

Dyson, R., \& Renk, K. (2006). Freshmen adaptation to university life: Depressive symptoms, stress, and coping. Journal of Clinical Psychology, 62, 1231-1244. doi:10.1002/jclp.20295

Field, A. (2013). Discovering statistics using IBM SPSS statistics (4th ed.). London, England: SAGE.

Gould, C., \& Ward, C.L. (2015). Positive parenting in South Africa: Why supporting families is key to development and violence prevention. Policy Brief, 77. Pretoria, South Africa: Institute for Security Studies. Retrieved from http://www.issafrica.org/publications/policy-brief/positive-parenting-in-south-africawhy-supporting-families-is-key-to-development-and-violence-prevention (Accessed December 2017).

Grolnick, W. S. (2003). The psychology of parental control: How well meant parenting backfires. Mahwah, NJ: Lawrence Erlbaum.

Grolnick, W. S., Kurowski, C. O., Dunlap, K. G., \& Hevey, C. (2000). Parental resources and the transition to junior high. Journal of Research on Adolescence, 10, 465-488.

Grolnick, W. S., \& Pomerantz, E. M. (2009). Issues and challenges in studying parental control: Toward a new conceptualization. Child Development Perspectives, 3, 165-170.

Grolnick, W. S., Price, C. E., Beiswinger, K. L., \& Sauck, C. C. (2007). Evaluative pressure in mothers: Effects of situation, maternal, and child characteristics on autonomy supportive versus controlling behaviour. Developmental Psychology, 43, 991-1002. doi:10.1037/0012-1649.43.4.991

Guay, F., Ratelle, C. F., \& Chanal, J. (2008). Optimal learning in optimal contexts: The role of self-determination in education. Canadian Psychology/Psychologie Canadienne, 49, 233-240.

Inguglia, C., Ingoglia, S., Liga, F., Lo Coco, A., Lo Cricchio, M. G., Musso, P., . . . Lim, H. J. (2016). Parenting dimensions and internalizing difficulties in Italian and U.S. emerging adults: The intervening role of autonomy and relatedness. Journal of Child and Family Studies, 25, 419-431. doi:10.1007/ s10826-015-0228-1

Joussemet, M., Koestner, R., Lekes, N., \& Landry, R. (2005). A longitudinal study of the relationship of maternal autonomy support to children's adjustment and achievement in school. Journal of Personality, $73,1215-1235$.

Joussemet, M., Landry, R., \& Koestner, R. (2008). A self-determination theory perspective on parenting. Canadian Psychology, 49, 194-200. doi:10.1037/a0012754

Kanengoni, H., Ngarambe, C. N., \& Buitendach, J. H. (2017). Psychological capital and work behaviourrelated outcomes among South African church ministers. South African Journal of Psychology. Advance online publication. doi:10.1177/0081246317729571

Katz, S., \& Somers, C. L. (2015). Individual and environmental predictors of college adjustment: Prevention and intervention. Current Psychology, 36(1), 56-65.

Lamb, M. E. (2012). Mothers, fathers, families, and circumstances: Factors affecting children's adjustment. Applied Developmental Science, 16, 98-111. doi:10.1080/10888691.2012.667344

Lourens, A., \& Smit, I. (2003). Retention: Predicting first year success. South African Journal of Higher Education, 17, 169-176.

Madu, S. N., \& Matla, M. Q. P. (2003). Illicit drug use, cigarette smoking and alcohol drinking behaviour among a sample of high school adolescents in the Pietersburg area of the Northern Province, South Africa. Journal of Adolescence, 26(1), 121-136. 
Mageau, G. A., Ranger, F., Joussemet, M., Koestner, R., Moreau, E., \& Forest, J. (2011). Validation of the Perceived Parental Autonomy Support Scale (P-PASS). Canadian Journal of Behavioural Science/ Revue canadienne des sciences du comportement, 47(3), 251-262.

Magnuson, K., \& Berger, L. M. (2009). Family structure states and transitions: Associations with children's well-being during middle childhood. Journal of Marriage and Family, 71, 575-591.

Marbell, K. N., \& Grolnick, W. S. (2012). Correlates of parental control and autonomy support in an interdependent culture: A look at Ghana. Motivation and Emotion, 37, 79-92.

McClelland, E., \& McKinney, C. (2016). Disruptive behavior and parenting in emerging adulthood: Mediational effect of parental psychopathology. Journal of Child and Family Studies, 25(1), 212-223.

Musick, K., \& Meier, A. (2010). Are both parents always better than one? Parental conflict and young adult well-being. Social Science Research, 39, 814-830. doi:10.1016/j.ssresearch.2010.03.002

Nixon, E., Greene, S., \& Hogan, D. (2015). "It's What's Normal for Me": Children's Experiences of Growing Up in a Continuously Single-Parent Household. Journal of Family Issues, 36(8), 1043-1061.

Parker, J. D., Hogan, M. J., Eastabrook, J. M., Oke, A., \& Wood, L. M. (2006). Emotional intelligence and student retention: Predicting the successful transition from high school to university. Personality and Individual Differences, 41, 1329-1336.

Pillay, A. L., \& Ngcobo, H. S. (2010). Sources of stress and support among rural-based first-year university students: An exploratory study. South African Journal of Psychology, 40, 234-240.

Quan, L., Zhen, R., Yao, B., \& Zhou, X. (2014). The effects of loneliness and coping style on academic adjustment among college freshmen. Social Behavior and Personality: An International Journal, 42, 969-977.

Rodríguez, M. S., Tinajero, C., \& Páramo, M. F. (2017). Pre-entry characteristics, perceived social support, adjustment and academic achievement in first-year Spanish university students: A path model. The Journal of Psychology, 151, 722-738.

Roman, N. (2011). Maternal parenting in single and two-parent families in South Africa from a child's perspective. Social Behaviour and Personality, 39, 577-586. doi:10.2224/sbp.2011.39.5.577

Rubin, A., \& Babbie, E. (2001). Research methods for social work (4th ed.). Belmont, CA: Wadsworth.

Schwartz, S. J., Zamboanga, B. L., Ravert, R. D., Kim, S. Y., Weisskirch, R. S., Williams, M. K., .. . Finley, G. E. (2009). Perceived parental relationships and health-risk behaviors in college-attending emerging adults. Journal of Marriage and Family, 71, 727-740.

Sharma, B. (2012). Adjustment and emotional maturity among first year college students. Pakistan Journal of Social and Clinical Psychology, 10(2), 32-37.

Soenens, B., \& Vansteenkiste, M. (2005). Antecedents and outcomes of self-determination in 3 life domains: The role of parents' and teachers' autonomy support. Journal of Youth and Adolescence, 34, 589-604. doi:10.1007/s10964-005-8948-y

Soenens, B., Vansteenkiste, M., \& Sierens, E. (2009). How are parental psychological control and autonomysupport related? A cluster-analytical approach. Journal of Marriage and Family, 71, 187-202.

Soenens, B., Vansteenkiste, M., \& Van Petegem, S. (2014). Let us not throw out the baby with the bathwater: Applying the principle of universalism without uniformity to autonomy-supportive and controlling parenting. Child Development Perspectives, 9, 44-49. doi:10.1111/cdep.12103

Sommer, M., \& Dumont, K. (2011). Psychosocial factors predicting academic performance of students at a historically disadvantaged university. South African Journal of Psychology, 41, 386-395.

Sun, Y., \& Li, Y. (2011). Effects of family structure type and stability on children's academic performance trajectories. Journal of Marriage and Family, 73, 541-556. doi:10.1111/j.1741-3737.2011.00825.x

Tavakol, M., \& Dennick, R. (2011). Making sense of Cronbach's alpha. International Journal of Medical Education, 2, 53-55.

Tavassolie, T., Dudding, S., Madigan, A. L., Thorvardarson, E., \& Winsler, A. (2016). Differences in perceived parenting style between mothers and fathers: implications for child outcomes and marital conflict. Journal of Child and Family Studies, 25, 2055-2068.

Terreblanche, M., \& Durrheim, K. (2004). Research in practice: Applied methods for the social sciences. Cape Town: University of Cape Town.

Vansteenkiste, M., \& Ryan, R. (2013). On psychological growth and vulnerability: Basic psychological need satisfaction and need frustration as a unifying principle. Journal of Psychotherapy Integration, 23, 263 280. doi:10.1037/a0032359 